\title{
In vitro clonal propagation of Nephrolepis
}

\section{A. Padhya}

Department of Botany, The M.S. University of Baroda, Baroda, India

Ferns are cultivated as ornamental plants because of their evergreen foliage. The present investigation deals with the successful application of tissue culture techniques as a powerful tool for the rapid and mass propagation, on a commercial scale, of two species of Nephrolepsis. In vitro grown $N$. cordifolia Presel and $N$. exaltata on $\mathbf{B}_{5}$ medium (Gamborg et al. 1968) were used for stolon explants.

Stolon segments grown on $\mathrm{B}_{5}$ medium containing IBA (indolebutyric acid) produced greenish proliferations along their entire margin within 2 weeks. These proliferations were produced due to the initiation of meristematic growth centres. These meristematic growth centres consisted of cells in their undetermined stage of development. At this crucial stage, they were transferred to $B_{5}$ medium supplemented with 6-benzylaminopurine. The incorporation of this cytokinin in the medium induced further growth and development of these meristematic cells, resulting in the formation of adventitious buds. Each bud primordium developed a typical shoot apical meristem. Each bud on transfer back to IBA medium regenerated into a complete plantlet. Thus, it became apparent that these adventitious buds behaved as 'asexual vegetative propagules'. Adopting this technology, numerous buds were produced at a time, thereby achieving more rapid clonal propagation. About 10,000 Nephrolepis plants were produced from a single stolon explant within 6 months.

To bring down the cost of production of ferns raised by tissue culture, sucrose and Difco-bacto agar from the medium were replaced by sugar and ordinary agar. Both these Nephrolepis species grown by this technique exhibited uniformity. Tissue culture has revolutionised fern propagation and because of its profitability has gained much popularity among the commercial fern growers.

Gamborg, O. L., Miller, R. A. and Ojima, K. 1968. Nutrient requirements of suspension cultures of soybean root cells. Exp. Cell. Res. 50, 151-158.

\section{Cryo SEM of reproduction in pteridophytes}

\author{
E. Sheffield, E. G. Cutter and W. A. Charlton \\ Department of Botany, University of Manchester, Oxford Road, \\ Manchester M13 9PL, UK.
}

Scanning electron micrographs can yield valuable data and provide threedimensional information about biological material. Conventional preparative techniques (such as freeze drying and critical point drying), however, regularly result in distortion, shrinkage and/or collapse of the fragile reproductive organs of pteridophytes. Plate 1 shows material prepared by low temperature freezing, and illustrates how the recent development of cryo SEM can be applied to yield excellent preservation. 